\title{
Does news on real Chinese GDP growth impact stock markets?
}

\author{
Philip Hans Franses \\ Heleen Mees
}

Econometric Institute Report 2010-41

\begin{abstract}
Real GDP growth in China follows a random walk. Also, it has often been suggested that China "cooks its books", that is to say that governmental officials in China manipulate economic statistics such as GDP growth rate to present the outside world a rosy picture (Foreign Policy, September 3, 2009). If such unreliability is known to stock traders, news on GDP should not impact stock market fluctuations or their volatility. We test this hypothesis for 12 series with daily stock market returns for the years 2006 to and including 2009.
\end{abstract}

Key words: Gross Domestic Product; China

JEL code: E01

Version: July 92010

This paper has been prepared for inclusion in a special issue of Applied Economics as a tribute to Sir Clive Granger.

We thank Stephanie Vermeer for excellent research assistance. The address for correspondence is Econometric Institute, Erasmus School of Economics, PO Box 1738 NL-3000 DR, Rotterdam, the Netherlands franses@ese.eur.nl, mees@ese.eur.nl 


\section{Introduction}

The quarterly real GDP growth data for China have interesting properties. One of these is that they are released quite rapidly after the relevant quarter, although China tends to have quite significant revisions of annual economic growth at a one year lag. Second, real GDP growth follows random walk properties, which means that the growth rates cannot be predicted through mere extrapolation. Third, it is often suggested that statistics in China are manipulated and therefore unreliable. The Wall Street Journal pointed out the discrepancy between Chinese GDP growth data and data on oil and electricity demand (May 29, 2009). In the first quarter of 2009, for example, 6.1 percent GDP growth coincided with a mere 3.0 percent growth in energy consumption. The Financial Times reported that the tally of GDP estimates provided by the 31 provincial and municipal governments for the first half of 2009 was significantly higher, about 10 percent, than the GDP figure released by the National Bureau of Statistics (August 5, 2009).

We study the consequences of these properties on stock market fluctuations. For this, we analyze an EGARCH model which includes 16 dummies concerning the announcement dates in the level equation and in the conditional volatility equation. The model is fitted to daily stock market returns data for 8 Asian stock markets and 4 US stock markets. According to the efficient market hypothesis (EHM), financial markets should respond only tepidly to news on GDP that is deemed unreliable.

The outline of our paper is as follows. In Section 2 we describe a few features of real GDP growth rates of China. In Section 3 we discuss our methodology and we present the results. Section 4 provides the general conclusion. Our main finding is that Chinese news has only a limited and also non-systematic impact on stock market fluctuations. 


\section{Real GDP growth in China}

Insert Figure 1 about here

Figure 1 gives the nominal levels of GDP in China as they are published each quarter. The data are cumulated, which means that the first quarter reports the data on the first quarter, whereas the second quarter concerns the sum of output in the first two quarters, and so on.

Insert Figure 2 about here

Figure 2 gives the real GDP growth rates. In Franses and Mees (2010) it is documented that this series follows a random walk. This is quite an unusual finding as most growth rates of real GDP data for industrialized countries can be described by simple time series models like ARMA, which implies that these figures can be predicted to some extent through extrapolation. When the data are a random walk, the best forecast is the most recent observation, hence a no-change forecast. In Table 1 we present the actual data and the no-change forecasts, as well as the forecast errors. Later on we will classify these forecast errors as negative or positive news to see if such news has an impact on stock market returns or stock market volatility.

Insert Table 1 about here

In Table 2 we give the announcement dates for the growth rates of real GDP for the US and for China. The actual dates will be used to create associated zero-one dummy variables in the models below. We observe that the release dates for the Chinese data lead the dates of US announcements.

Insert Table 2 about here 
As said, the best forecast for real growth rates for Chinese GDP using extrapolation is the no-change forecast. This implies that traders all can rely on the same information concerning expected growth rates. Surprises in announcements would then be equally important for all traders, and nobody can make better forecasts. The distribution of past forecast errors can be instrumental to assign whether new GDP quotes are large or small surprises. In the analysis below we will take absolute forecast errors exceeding 1.0 as large. So, traders may assign different interpretation to forecast errors, but they will not be able to create better forecasts than the no-change forecasts.

Professional traders generally will not rely exclusively on historic GDP data to make forecasts for real GDP growth. Data regarding payrolls, manufacturing, exports and other leading economic indicators will help traders to make their predictions. If the official GDP data are considered to be untrustworthy, however, financial markets should only respond tepidly to surprises in announcements of official data.

Taking altogether this suggests that news on real GDP growth rates of China would not have a large impact on stock market returns nor on stock market volatility. We will put this suggestion to a test in the next section.

\section{Modeling stock markets}

In the section we analyze whether the announcements concerning real GDP growth in China has an impact on stock market returns or stock market volatility.

\subsection{The data and the model}

We consider four years of daily stock market returns. These are India BSE, Nikkei 225, Hang Seng, Straits (Singapore), Korea, LQ45 (Indonesia), Shanghai, and Shenzhen as the

leading Asian stock markets, and the S\&P500, Nasdaq, Dow Jones and Russell2000 as the US stock markets. For the levels equation for the returns $y_{t}$ we consider 


$$
y_{t}=\mu+\sum_{i=1}^{16} \delta_{i}^{\text {USA }} D_{i, t}^{\text {USA }}+\sum_{i=1}^{16} \delta_{i}^{\text {China }} D_{i, t}^{\text {China }}+u_{t}
$$

where the zero-one dummy variables $D_{i, t}^{U S A}$ correspond with the dates in the second column of Table 2 and the zero-one dummy variables $D_{i, t}^{\text {China }}$ with the dates in the third column. Below we will be interested in the hypotheses that $\delta_{1}^{U S A}=\ldots=\delta_{16}^{U S A}=0$ and that $\delta_{1}^{\text {China }}=\ldots=\delta_{16}^{\text {China }}=0$, and for that we will use a joint Wald test. Note that we import the dates such that they match the proper time zones. Chinese news will reach Asia during the very same day, while it reaches the American time zone the next day. The reverse holds for US news.

The next model we consider as in $\operatorname{EGARCH}(1,1)$ equation, which comprises the following two equations, that is

$$
y_{t}=\mu+z_{t} \sqrt{h_{t}}
$$

with

$$
\log h_{t}=\omega+\theta z_{t}+\lambda\left(\left|z_{t}\right|-E\left(\left|z_{t}\right|\right)\right)+\alpha \log h_{t-1}+\sum_{i=1}^{16} \lambda_{i}^{\text {USA }} D_{i, t}^{\text {USA }}+\sum_{i=1}^{16} \lambda_{i}^{\text {China }} D_{i, t}^{\text {China }}
$$

Below we are interested in the hypotheses $\lambda_{1}^{\text {USA }}=\ldots=\lambda_{16}^{\text {USA }}=0$ and $\lambda_{1}^{\text {China }}=\ldots=\lambda_{16}^{\text {China }}=0$, and again we will use a Wald test. Estimation will be carried out using the Eviews program. Note that we cannot replace (2) by (1) as then the parameters for the dummy variables are not identified.

Insert Tables 3 and 4 about here 


\subsection{The results, general}

The Wald test values for the hypotheses concerning the conditional volatility equations are given in Table 3. We see that stock market returns in 4 of the 8 Asian indexes react to US news, while this occurs for only 2 of the 8 concerning Chinese news. At the same time, US stock market returns do not significantly react to US news or to Chinese news.

It is well known that at the very same day of presentation of national accounts figures the response at the level of returns can be small, but perhaps more response is there to be expected at the level of volatility. Table 4 presents the relevant Wald test results, and indeed, news announcements do seem to have more effect on volatility than on returns. For 5 of the 12 stock markets Chinese news (and US news alike) have an impact on volatility. The S\&P500 and Nasdaq respond about similar to both US and Chinese news. This also holds for the LQ45 of Indonesia, where news seems to imply the largest effects for volatility.

\section{Insert Table 5 and 6}

\subsection{The results, more refined}

Finally, we examine which of the announcement dates for Chinese news have most impact, and whether this news could have been considered as positive or negative. In Table 5 we classify the forecast errors of real GDP growth accordingly. In Table 6 we give the dates for which the news has an individual significant impact on stock market volatility.

\section{Insert Table 7 about here}

Table 6 shows that if news has an impact on conditional volatility it usually makes this volatility to decrease, and hence to calm down stock market fluctuations. A second observation of Table 6 is that it does not seem to matter much whether this news is positive or negative. In the panel for an increase in volatility, we see that it is only 
positive or no news that makes volatility increase (in, as must be said, a very small amount of cases). Table 6 also shows that out of the 16 (news dates) times 12 (stock markets) possibly significant outcomes, only 24 are significant, which amounts to a fraction of $12.5 \%$. Table 7 shows that this percentage for US news is $19.8 \%$ while for Germany it is $10.4 \%$. At the same time, we observe from Table 6 that the nature of the news that makes volatility to decrease can be positive or negative, and there is no systematic pattern.

\section{Conclusion}

There is a limited effect of Chinese news on world stock markets (12.5\% of the news dates there is a significant impact) compared to US news (19.8\% of the news dates there is a significant impact). Stock market returns in 4 of the 8 Asian stock indexes react to US news, while they react in only 2 of the 8 Asian stock indexes to Chinese news. US stock market returns do not significantly react to either US news or to Chinese news. US and Chinese news have a similar impact on stock market volatility.

We started this paper discussing the fact that Chinese real GDP follow a random walk, and the fact that Chinese data are often deemed as not trustworthy. We suggested that these properties imply that stock markets respond only tepidly to Chinese news as traders might be expected to take the official announcements with a pinch of salt. Indeed we found that stock markets respond less to Chinese news than to US news.

An alternative explanation for the fact that stock markets respond more tepidly to Chinese news than to US news may be the size of the Chinese economy. We included in the last batch (table 7) German data that could serve as a benchmark this hypothesis. The German authorities are known for their punctuality. Hence few traders will doubt the trustworthiness of the German GDP data.

The stock market's timid response to the German data shows that the relative size of the economy is a quite plausible explanation. Stock indexes respond less to German news than to US news while German and US data are deemed equally reliable. German GDP is about a quarter of US GDP. 
Measured in current US dollars the German economy is almost equal the size of the Chinese economy (see Table 8A). German and Chinese news significantly impacted world stock markets on $10.4 \%$ respectively $12.5 \%$ of the news dates (compared to $19.8 \%$ for US news). The relative size of the Chinese economy measured in current US dollars may be a plausible explanation for the fact that stock markets respond less often to Chinese news (12.5\%) than to US news (19.8\%).

If GDP is measured on a purchasing-power-parity (PPP) base, the Chinese economy is three times the size of the German economy. (see Table 8B). In that case the size of the Chinese economy cannot fully account for the fact that stock markets respond less often to Chinese news (12.5\%) than to US news (19.8\%). The unpredictability/unreliability of Chinese GDP data may then serve as an additional explanation. 


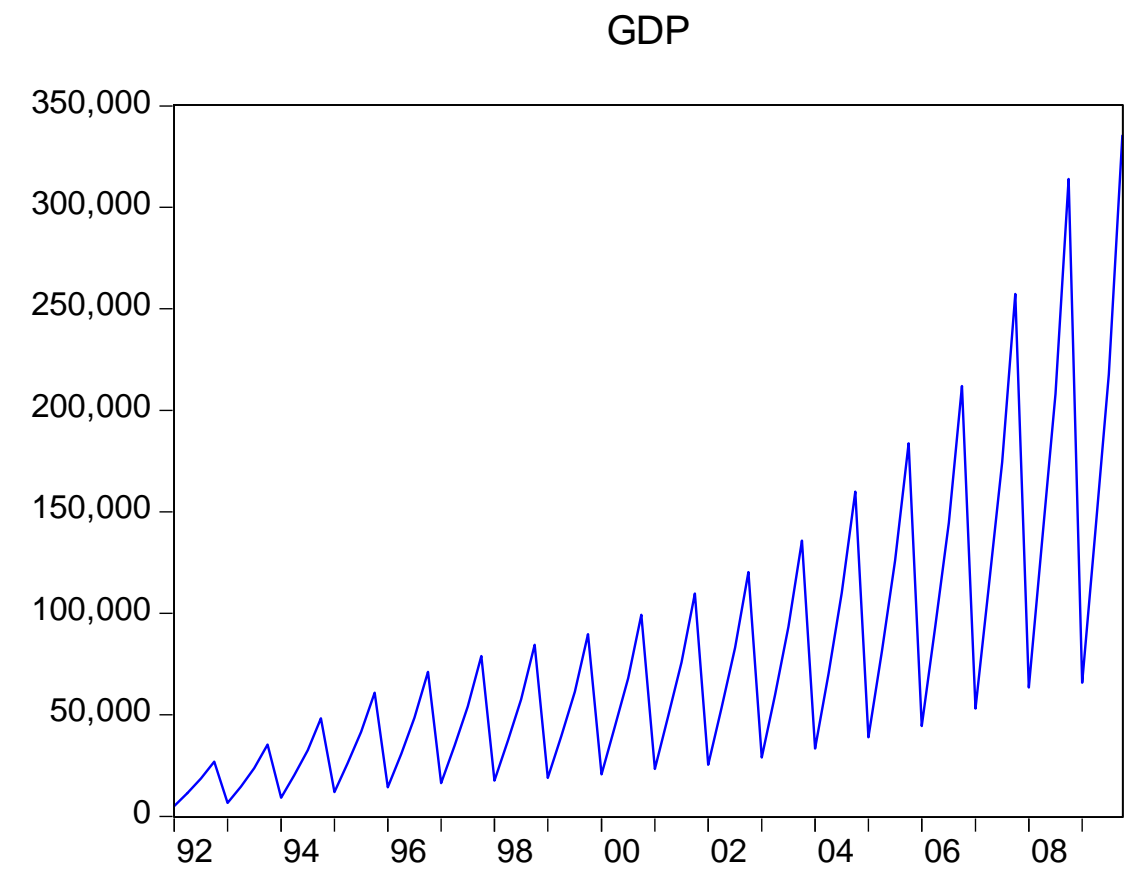

Figure 1: Nominal GDP (levels) in China, 1992Q1-2009Q4 


\section{GROWTH}

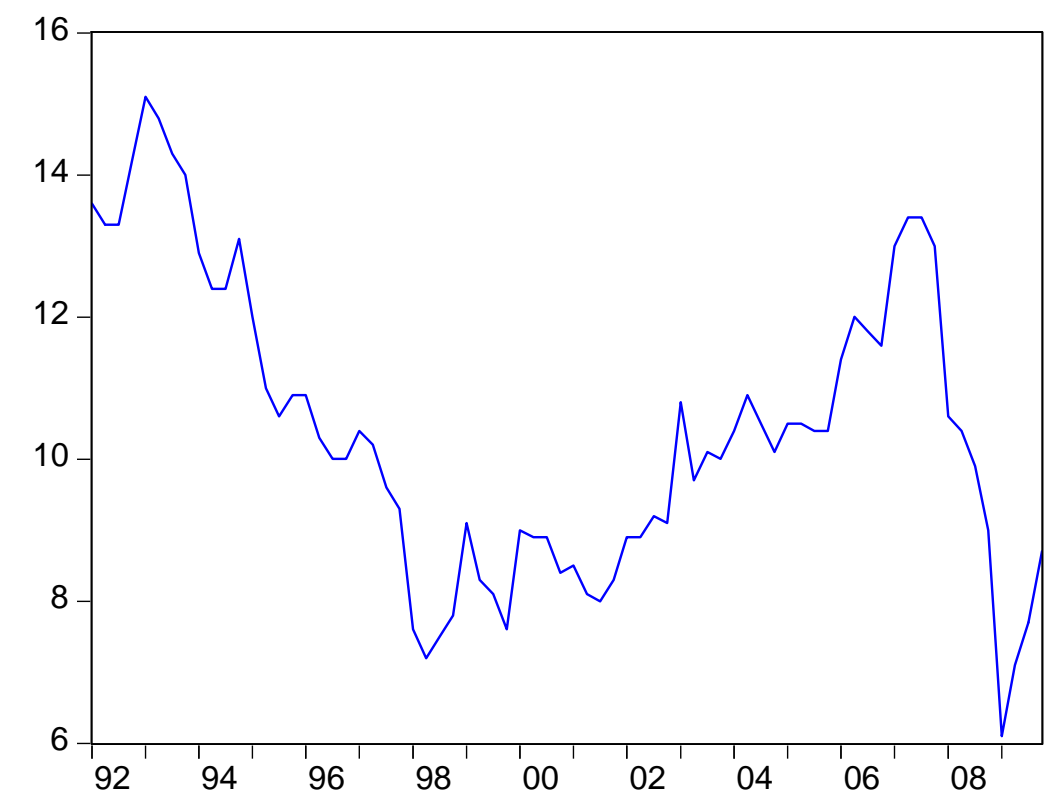

Figure 2: Quarterly real growth rates of GDP in China, 1992Q1-2009Q4. 
Table 1: The real GDP figures, as they are available from the National Bureau of Statistics of China, and the forecasts that follow from a random walk.

$\begin{array}{cccc}\text { Quarter } & \begin{array}{c}\text { REAL } \\ \text { GROWTH }\end{array} & \begin{array}{c}\text { NO - CHANGE } \\ \text { FORECAST }\end{array} & \begin{array}{c}\text { FORECAST } \\ \text { ERROR }\end{array} \\ \text { 2005Q4 } & 10.4 & 10.4 & 0.0 \\ \text { 2006Q1 } & 11.4 & 10.4 & 1.0 \\ \text { 2006Q2 } & 12.0 & 11.4 & 0.6 \\ \text { 2006Q3 } & 11.8 & 12.0 & -0.2 \\ \text { 2006Q4 } & 11.6 & 11.8 & -0.2 \\ \text { 2007Q1 } & 13.0 & 11.6 & 1.4 \\ \text { 2007Q2 } & 13.4 & 13.0 & 0.4 \\ \text { 2007Q3 } & 13.4 & 13.4 & 0.0 \\ \text { 2007Q4 } & 13.0 & 13.4 & -0.4 \\ \text { 2008Q1 } & 10.6 & 13.0 & -2.4 \\ \text { 2008Q2 } & 10.4 & 10.6 & -0.2 \\ \text { 2008Q3 } & 9.90 & 10.4 & -0.5 \\ \text { 2008Q4 } & 9.00 & 9.90 & -0.9 \\ \text { 2009Q1 } & 6.10 & 9.00 & -2.9 \\ \text { 2009Q2 } & 7.10 & 6.10 & 1.0 \\ \text { 2009Q3 } & 7.70 & 7.10 & 0.6 \\ \text { 2009Q4 } & 8.70 & 7.70 & 1.0\end{array}$

Source: http://www.stats.gov.cn/english (Consulted: January 22 2010)

The data in this table are calculated at constant prices, and are relative to the same period of the preceding year $=100$ 


\section{Table 2:}

Dates with first announcements concerning the flash values of GDP growth in the previous quarter

\begin{tabular}{|c|c|c|c|}
\hline Year & USA & China & Difference \\
\hline \multirow[t]{4}{*}{2006} & January 27 & January 25 & 2 \\
\hline & April 28 & April 20 & 8 \\
\hline & July 28 & July 20 & 8 \\
\hline & October 27 & October 24 & 3 \\
\hline \multirow[t]{4}{*}{2007} & January 31 & January 25 & 6 \\
\hline & April 27 & April 18 & 9 \\
\hline & July 27 & July 18 & 9 \\
\hline & October 31 & October 23 & 8 \\
\hline \multirow[t]{4}{*}{2008} & January 30 & January 24 & 6 \\
\hline & April 30 & April 17 & 13 \\
\hline & July 31 & July 17 & 14 \\
\hline & October 30 & October 21 & 9 \\
\hline \multirow[t]{4}{*}{2009} & January 30 & January 22 & 8 \\
\hline & April 29 & April 16 & 13 \\
\hline & July 31 & July 16 & 15 \\
\hline & October 29 & October 22 & 7 \\
\hline
\end{tabular}


Table 3:

Wald test values (and p values) for joint significance of sixteen dummy variables measuring days with GDP announcements for the levels equation of regression model (with an intercept) model for stock returns, 01/03/2006-11/24/2009 (correcting for time zones)

US news

Chinese news

Stock market

$\begin{array}{lllll}\text { India BSE } & 12.41 & (0.715) & 13.96 & (0.602) \\ \text { Nikkei 225 } & \mathbf{4 1 . 8 9} & \mathbf{( 0 . 0 0 0 )} & 10.60 & (0.833) \\ \text { Hang Seng } & \mathbf{4 4 . 1 0} & \mathbf{( 0 . 0 0 0 )} & 38.16 & \mathbf{( 0 . 0 0 1 )} \\ \text { Straits (Singapore) } & \mathbf{4 0 . 2 6} & \mathbf{( 0 . 0 0 1 )} & 21.60 & (0.157) \\ \text { Korea } & \mathbf{1 2 5 . 9} & \mathbf{( 0 . 0 0 0 )} & 13.12 & (0.664) \\ \text { LQ45 (Indonesia) } & 20.45 & (0.201) & 34.45 & (\mathbf{0 . 0 0 5 )}) \\ \text { Shanghai } & 18.85 & (0.276) & 10.98 & (0.811) \\ \text { Shenzhen } & 18.03 & (0.322) & 11.47 & (0.780) \\ & & & & \\ \text { S\&P500 } & 10.28 & (0.852) & 7.811 & (0.954) \\ \text { Nasdaq } & 8.743 & (0.924) & 16.51 & (0.418) \\ \text { Dow Jones } & 8.818 & (0.921) & 8.376 & (0.937) \\ \text { Russell2000 } & 12.63 & (0.700) & 10.31 & (0.850)\end{array}$


Table 4:

Wald test values (and p values) for joint significance of sixteen dummy variables measuring days with GDP announcements for the conditional volatility equation of an

EGARCH(1,1) model for stock returns, 01/03/2006-11/24/2009, with t-distributed innovations (correcting for time zones)

US news

Stock market

India BSE

Nikkei 225

Hang Seng

Straits (Singapore)

Korea

LQ45 (Indonesia)

Shanghai

Shenzhen

S\&P500

Nasdaq

Dow Jones

Russell2000
29.81 (0.019)

362.4 (0.000)

24.80 (0.073)

6.919 (0.975)

17.01 (0.385)

745.6 (0.000)

2.425 (1.000)

2.131 (1.000)

36.50 (0.003)

$173.2(0.000)$

24.93 (0.071)

9.084 (0.910)
Chinese news
24.65 (0.076)

21.12 (0.174)

373.1 (0.000)

7.084 (0.972)

7.318 (0.967)

597.5 (0.000)

0.243 (1.000)

32.20 (0.009)

30.61 (0.015)

49.09 (0.000)

21.13 (0.174)

15.64 (0.478) 
Table 5: Dates with first announcements concerning the flash values of GDP growth in the previous quarter and indication if realization was higher (++ for larger than 1.0 forecast errors, or + for forecast errors in between 0.0 and 1.0) or lower (-- for larger than -1.0 forecast errors or - forecast errors in between 0 and -1.0 ) than expected (based on random walk forecast for real GDP growth, see Table 1)

Year

2006

2007

2008

2009
Nature of the news

January 25

0

April 20

July 20

October 24

January 25

April 18

July 18

October 23

January 24

April 17

July 17

October 21

January 22

April 16

July 16

October 22
$++$

$+$

0

$+$

$+$
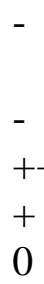

$+$

$+$ 
Table 6: Detailed results concerning increase of decrease in conditional volatility due to Chinese news on specific days (increase in volatility is due to worse than expected news, and a decrease in volatility due to better than expected news)

Stock market

Increase

Decrease

\section{Asia}

India BSE

January 252007 (-)

April 172008 (--)

Nikkei 225

July $202006(+)$

October 232007 (-)

Hang Seng

July $162009(++) \quad$ July $202006(+)$

April $182007(++)$

LQ45 (Indonesia)

January 252006 (0)

October 242006 (-)

January 252007 (-)

April $182007(++)$

October 212008 (-)

April 162009 (--)

October $222009(+)$

Shenzhen

January 252006 (0) July 182007 (+)

\section{USA}

S\&P500

April 172008 (--)

October $212008(-)$

Nasdaq

April $202006(+)$

January 252006 (0)

July $182007(+)$

October $222009(+)$

Dow Jones

October 242006 (-)

Russell2000

July $182007(+)$ 
Table 7: Number of days (out of the 16) where US and German news has a significant impact on conditional volatility

$\begin{array}{lll} & \text { US news } & \text { German news } \\ \text { India BSE } & 2 & 2 \\ \text { Nikkei 225 } & 10 & 2 \\ \text { Hang Seng } & 1 & 2 \\ \text { Straits (Singapore) } & 1 & 1 \\ \text { Korea } & 2 & 1 \\ \text { LQ45 (Indonesia) } & 11 & 1 \\ \text { Shanghai } & 0 & 2 \\ \text { Shenzhen } & 0 & 3 \\ & & \\ \text { S\&P500 } & 3 & 2 \\ \text { Nasdaq } & 5 & 2 \\ \text { Dow Jones } & 2 & 1 \\ \text { Russell2000 } & 1 & 1\end{array}$


Table 8A: Gross domestic product in current US dollars (billions)

$\begin{array}{llll} & \text { China } & \text { Germany } & \text { United States } \\ 2006 & 2657.84 & 2919.51 & 13398.93 \\ 2007 & 3382.45 & 3328.18 & 14007.65 \\ 2008 & 4327.45 & 3673.11 & 14441.43 \\ 2009 & 4757.74 & 3235.46 & 14266.20 \\ 2006-2009 & 15125.48 & 13156.26 & 56184.21\end{array}$

Table 8B: Gross domestic product based on purchasing power parity (PPP) as share of world GDP (\%)

$\begin{array}{lccc} & \text { China } & \text { Germany } & \text { United States } \\ 2006 & 10.06 & 4.39 & 21.66 \\ 2007 & 10.72 & 4.29 & 21.07 \\ 2008 & 11.35 & 4.21 & 20.61 \\ 2009 & 12.05 & 4.09 & 20.02 \\ 2006-2009 & 11.05 & 4.24 & 20.84\end{array}$

(Source: IMF) 


\section{References}

Engle, Robert F. (1982), Autoregressive Conditional Heteroskedasticity with Estimates of the Variance if United Kingdom Inflation, Econometrics, 50, 987-1008.

Franses, Philip Hans and Heleen Mees (2010), Approximating the DGP of China's Quarterly GDP, Econometric Institute Report 2010-04, Erasmus School of Economics.

Nelson, Daniel B (1991), Conditional Heteroskedasticity in Asset Returns: A New Approach, Econometric 59, 347-370. 